\title{
ALTAR in action: knowledge management
}

\author{
Hanifa Shah ${ }^{1}$, \\ Alan Eardley ${ }^{1}$ and \\ Trevor Wood-Harper ${ }^{2,3}$ \\ ${ }^{1}$ Staffordshire University, FCET, The Octagon, \\ Stafford, U.K.; ${ }^{2}$ Manchester Business School, \\ Manchester University, Manchester, U.K.; \\ ${ }^{3}$ Australian National University, College of \\ Business and Economics, Canberra, Australia
}

Correspondence: Hanifa Shah, Staffordshire University, FCET, The Octagon, Stafford, ST18 OAD, U.K.

Tel: + 44 (0)1785 353446;

E-mail: h.shah@staffs.ac.uk
Received: 10 May 2007

Revised: 24 September 2007

Accepted: 27 September 2007

\begin{abstract}
This paper describes the knowledge management (KM) aspects of an action research (AR) project that took place in a large U.K. manufacturing organisation, Britvic Soft Drinks Ltd. The ALTAR (Achieving Learning Through Action Research) approach described in an earlier paper was developed through the KM project described in this paper. The ALTAR approach was intended to facilitate organisational learning and academic research and the study involved a number of AR cycles at different levels of the collaborating organisation. Theoretical concepts were taken from the academic literature and were developed for practical use and fed back into the academic research. The knowledge value chain, in particular, helped the organisation to focus on the essential aspects of KM. The research-led thinking was useful in helping Britvic staff to define and understand the importance of knowledge, to identify what knowledge assets they owned and to understand how that knowledge could be harnessed. The research facilitated individuals' understanding of how better to access the knowledge of others and to share their own knowledge to benefit the whole organisation. From an academic point of view, the AR project facilitated academic research, stimulated organisational change and learning provided useful material for research outputs, teaching and learning and promoted future research opportunities.

European Journal of Information Systems (2007) 16, 77I-779.

doi: I0. I057/palgrave.ejis.300072 I
\end{abstract}

Keywords: action research; knowledge management; knowledge value chain; information systems; organisational learning

\section{Introduction}

We are living in what is recognised as the 'knowledge age'. Organisations need to understand what knowledge resources they have and how best to manage and exploit these. There is a wealth of academic theories and ideas on the topic of knowledge and its management. Less obvious are practically relevant tools and concepts that produce useful business outcomes. Information systems (IS) as a discipline embodies both theory and practice. Technologies, both hardware and software, are radically changing the way people use information and knowledge in a practical sense. This paper reports work that is concerned with theory and practice, which utilises action research (AR) to facilitate the research, practical change and organisational learning. AR facilitates these multiple requirements as it combines in-depth theoretical development and improvement with practical benefits for the participating company of managed change and organisational learning. The AR research approach used in the knowledge management (KM) research project with Britvic is described in more detail in Shah et al. (2007). The present paper describes the KM aspects of the project.

Before the AR project began, Britvic had been conducting a study into the use of KM technology and a decision had been made (with the advice of vendors and external consultants) to acquire KM software. This 
'techno-centred' approach to KM development is not uncommon. Orlikowski indicates the importance of technology to $\mathrm{KM}$ in organisations in 'scaffolding' (i.e. providing support for) the 'process of knowing' and shows how, '...knowing in practice is materially scaffolded with technological artefacts' (Orlikowski, 2006). However, it is also pointed out that it is necessary 'to break down the conventional distinctions between the social and the material' (Swan, 2006). In other words, KM technology cannot be considered in isolation from the social processes that govern its use. Therefore, a research study into the applicability of KM to the social system of Britvic was recommended.

At that time, little academic research had been done to investigate the application of KM in the manufacturing sector in the U.K. This situation still applies, although studies in the U.S.A. have been reported recently (Erat et al., 2006; Howard-Grenville \& Carlile, 2006; Topi et al., 2006) What was lacking was an agreed definition of $\mathrm{KM}$, a general understanding within the organisation of the potential of $\mathrm{KM}$ and what was in fact required from KM technologies. The management of Britvic also felt that the organisation needed to understand the implications of the exploitation of $\mathrm{KM}$ and the adoption of $\mathrm{KM}$ technology for its existing well-developed IS planning and development strategies. In other words, there was an acceptance that it was more important for the organisation to learn as much as it could about the knowledge that it had and the potential that there may be for using this knowledge in commercial terms. This could be summarised by the phrase used by one of the managers, 'The importance of knowing what Britvic knows' and this 'audit' of organisational knowledge has been recognised as a major problem for some time (O'Dell \& Grayson, 1998). It was also important to foster an understanding of $\mathrm{KM}$ in the organisation and to promote a 'KM culture'. Contact between the authors and various local companies and personal research had led the researchers to suspect that many organisations were having KM technologies 'sold' to them without them also acquiring a proper understanding of the implications and meaning of $\mathrm{KM}$ in their organisations.

From a researchers' perspective it was necessary to develop academic conclusions about KM from the industry-based research project. The possibility of carrying out the research that is presented in this paper arose from contact between Britvic and the first author. The initiation of the project and the decision to employ an AR approach are described in Shah et al. (2007). The project at Britvic included research into a number of areas of KM (including the development of frameworks and tools for capturing and structuring organisational knowledge) that were reported at the early stages (Sharp et al., 2002, 2003, 2005). The research produced very detailed and specific processes and recommendations for managing knowledge in a particular context (Sharp, 2004). This paper describes the results of the authors' continuing research into $\mathrm{KM}$ (including at Britvic) that are presented in a more generalised way, that may provide some useful pointers to improving $\mathrm{KM}$ practices in a range of organisations and situations.

\section{The importance of KM}

Any large and complex organisation such as Britvic owns a considerable amount of knowledge, such as the methods of manufacturing its products and ways of delivering better customer service. Until the late 20th century, knowledge would be localised within specialist parts of an organisation (e.g. individuals and departments), would be strictly segregated according to organisational level (e.g. 'shop-floor' or boardroom) and would often be 'hoarded' as a source of personal power or security. Today, knowledge is increasingly considered to be an organisational asset (Carneiro, 2000) and it is assumed that every experience an individual has is potentially reusable by many other individuals in the same organisation (Basili \& Rombach, 1991). Usually such organisations aim to exploit this knowledge for competitive advantage by facilitating the creation of new knowledge and the effective sharing and utilisation of existing knowledge (Abell \& Oxbrow, 2001), 'Identifying, managing, and transferring knowledge and best practices has worked for some companies, sometimes saving or earning them literally billions' (O'Dell \& Grayson, 1998).

The potential value of this organisational knowledge, and the difficulty in acquiring and replicating it, makes it a strategic commodity in many sectors (e.g. Sharkie, 2003; Susarla et al., 2003), although it is pointed out that it is not the possession of knowledge that confers the advantage, but the way in which the knowledge is deployed to 'add value' to its future use (Teece, 1998). Although the knowledge is possessed by (and often resides within) individuals, the possession of knowledge by individuals cannot guarantee this 'added value', as individuals are transferable between firms and may not divulge or integrate the knowledge they hold with that held by others (Grant, 1996). There is also the problem of change, particularly in technology-driven organisations as the 'rate of change in technologies exceeds the time to develop subject matter experts, training courses, and human resource interventions' (Marler, 1999).

The basic problem with research into $\mathrm{KM}$ is the ambiguity and variety of the concept of knowledge itself. It is difficult to study any topic without arriving at a general agreement among the participants of the definition and characteristics of the subject under study. Polanyi (1967) originally identified the explicit and tacit categories of knowledge. It was apparent that Britvic would 'own' knowledge in both categories. Research into explicit knowledge is relatively straightforward as this category consists of knowledge that is easily structured and articulated and therefore is commonly recorded in documents and records. Analysis of these documents and records (often using a form of case study research) will allow the knowledge to be captured and codified (e.g. Jennex, 2005). This is typically 'organisational' 
knowledge that is collected in, and disseminated by, formal organisational IS. Research into tacit knowledge, however, is much more problematic in research terms as it is of a personal and unstructured nature, and that informal sources of knowledge are often overlooked in an organisational context (Topi et al., 2006).

Tacit knowledge is therefore often difficult to articulate and to share, although exploitation of this type of knowledge is held to be the more important for the success of an organisation (Nonaka \& Konno, 1998). It is frequently based on knowledge that is acquired personally - technical skills, experience and expertise and is usually exhibited informally in 'real-time' events such as unforeseen situations where the knowledge is used or applied. Other researchers identify a further category of knowledge termed implicit knowledge (e.g. Newman \& Conrad, 2000), which is knowledge that can be made explicit (e.g. codified or formalised) but which has not yet been treated in this way. It is important to note that tacit and implicit knowledge cannot be studied post hoc (i.e. by the case study method), but may be more suited to the use of the AR method (Shah et al., 2007).

The process of managing this knowledge emerged (Wiig, 1997) from the 'knowledge centric' view of the firm in the technical (e.g. Prusak, 2001) and the strategic management (e.g. Alavi \& Leidner, 2001) literature. According to Teece (1998) this knowledge is embedded in an organisation's business routines and processes, while others (e.g. Spender, 1996) identify and emphasise the role of the individual. These views are not necessarily mutually inclusive, as knowledge is clearly embedded in the minds of individuals (May \& Taylor, 2003), and yet is capable of being integrated in a way that makes it more effective (Grant, 1996) and recorded in a way that enables it to be interpreted more meaningfully (Kelleher \& Levene, 2001). It is therefore important to study both individuals and processes in researching $\mathrm{KM}$ in Britvic. A problem with any research into $\mathrm{KM}$ is the nature of knowledge itself.

Knowledge is difficult to define (Sveiby, 1997; Beckman, 1999), and cannot be observed directly (Polanyi, 1967). It is constantly changing, being updated regularly (Boisot, 1998; Speigler, 2000) and its effectiveness is difficult to measure in practice (Liebeskind, 1996). KM is defined in this paper as 'the overall task of managing the processes of knowledge creation, storage and sharing'. This includes identifying the current state of knowledge in the organisation ('knowing what we know'), the determination of knowledge needs ('finding what we need to know') and the improvement of knowledge processes in order to address these needs.

\section{The research approach}

A general overview of the various forms of AR and their characteristics is described in Baskerville \& Wood-Harper (1998) and experience of the AR approach, ALTAR (Achieving Learning Through Action Research), in the $\mathrm{KM}$ project at Britvic is discussed in Shah et al. (2007). It was noted that the $\mathrm{AR}$ approach required a close collaborative relationship between the researchers and the participating subjects (and their respective organisations) in order to be successful. The first stages of the KM project showed that it was possible to establish this relationship with careful planning and a formal approach to project initiation (Shah et al., 2007) and the research continued to confirm the relationship between KM and organisational learning that has been suggested elsewhere (e.g. Buckler, 1998). In general, AR was found to be a suitable method for research into KM because of the links between AR, KM and organisational learning. It is observed that $\mathrm{KM}$ promotes organisational learning by capturing, processing and sharing personal and functional knowledge in a way that can benefit the whole organisation (Argyris, 1999). Also, organisational learning informs the actions of the AR through the research process by participating in the identification of targets for action and the joint suggestion of goals for the research (Jae, 2004). In turn, AR creates an improvement in KM within the organisation through a change process based on an iterative improvement of knowledge assets, knowledge actions and a heightened appreciation of knowledge outcomes (Figure 1).

It was planned to conduct the $\mathrm{KM}$ project at three levels and to break the project down into a number of cycles (Shah et al., 2007). This 'maps onto' models of KM that are similarly structured into three levels (see Figure 2):

- The first level of $\mathrm{KM}$ is the 'knowledge context' - the management of the general conditions relating to the use of knowledge in the organisation. This includes arriving at knowledge definitions, establishing an awareness of knowledge requirements and identifying the external influences on the knowledge process such as management and environmental factors.

- The second level is the knowledge process itself - the provision of assistance for the direct, inter-human knowledge actions, for example, maintaining knowledge assets, the actions that can be carried out to manipulate the knowledge and the production of knowledge outcomes.

- The third level is the achievement of the knowledge potential through the generation and distribution of knowledge outcomes, often coded into artefacts, for example, documents, training, videos or communicated verbally to achieve the desired knowledge potential.

In order to achieve the project objectives the research team produced phases or sets of tasks that matched the levels of the research. The first of these would be to agree the project context among the stakeholders in the research project - the managers and knowledge workers and to facilitate producing working definitions of relevant knowledge concepts and terms within the context of the project. The importance of identifying knowledge processes and 'sequences of use' of knowledge 


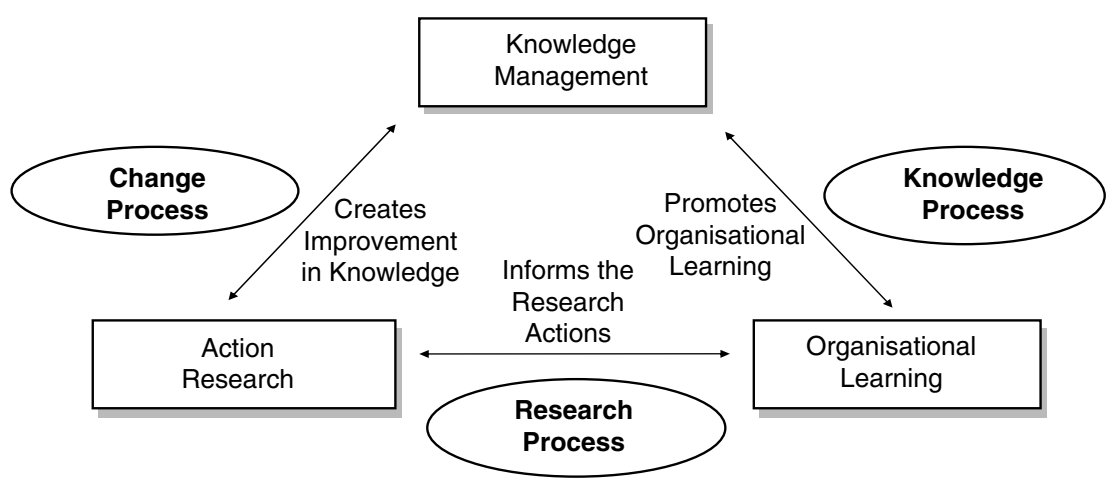

Figure 1 Relationship between knowledge management, organizational learning and action research.

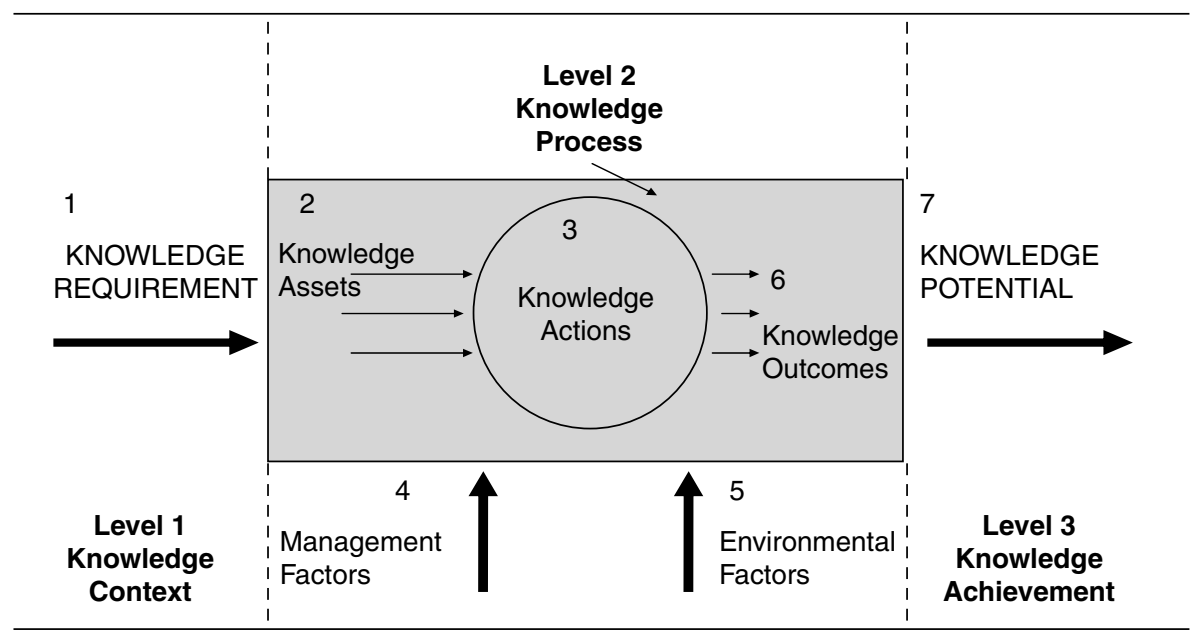

Figure 2 KnoVal: The knowledge value chain.

within Britvic was recognised as well as the prioritising of the project. This would be used to determine the likely impact of the KM project on IS development within Britvic leading to recommending a plan of action and producing the results of the research project for the University. Each of these levels of the research is discussed in more detail below.

\section{The knowledge context}

The first level of the research project addressed the issue of the variety of definitions of knowledge in the literature and within Britvic. Many definitions (e.g. Alavi \& Leidner, 2001; Hildreth \& Kimble, 2002) refer to the importance of the human element in defining, creating and understanding knowledge. Most definitions of knowledge embrace a number of issues. First, knowledge is multifaceted and complex, having hard and soft aspects that are 'inextricable woven' and often inseparable (Hildreth \& Kimble, 2002). This is conveniently illustrated by the example of the knowledge of a language. To a native speaker, the knowledge is 'soft' or implicit/tacit, being used at an intuitive level. To the writer of a language textbook, the knowledge is 'hard', being based on rules of grammar, syntax and vocabulary, yet the writer is also a native speaker. Most 'knowledge workers' in Britvic are in this position. Second, knowledge is dynamic and the definition and value of knowledge change over time. The value of an item of knowledge is greatest when it allows decisions to be made and actions to be taken that have benefit (e.g. to Britvic). Therefore currency is important and knowledge can become 'out of date' and lose its value. Third, knowledge is variable according to context. Context (or 'background') is created by combining knowledge from different sources and merging new knowledge with existing knowledge, possibly from tacit, implicit and explicit sources. This context, for Britvic, is related to 'organisational learning'. Finally, it was apparent that knowledge within Britvic (in all categories) can be shared if it can be articulated.

The project began by trying to increase the relevance of the research by engaging the staff from one of the business functions of Britvic in defining knowledge concepts according to their common or shared context 
- their 'world of work'. This was done by involving a sample of the staff of Britvic in a series of 'workshops' that were facilitated by the researchers. Staff members (knowledge workers and managers) were encouraged to contribute to the discussion and to discuss the utility and accuracy of their context and definitions. The researchers (as facilitators) 'kept the discussions moving' and recorded the results. The context was agreed to be, 'The management of "Brand X" across the marketing and sales functions for one year'. In this context the agreed definition of knowledge was,

The integration and reuse of ideas, experience, skills, intuition and "lessons learned" (in any way that) influences our problemsolving, decision-making (processes) and the way we work to create tangible outcomes of brand value and business worth.

\section{The knowledge value chain: KnoVal}

The researchers have developed a model, KnoVal, of the knowledge process that represents one form of the knowledge value chain (see Figure 2). The model is based on Holsapple \& Joshi (2001) and consists of the following components:

1. A knowledge requirement, for example, a decision that needs to be made or an action implemented that initiates the knowledge process.

2. Knowledge assets, that is, information relevant to the knowledge context is 'called up' and marshalled until the knowledge worker is satisfied that sufficient knowledge is available for the purpose.

3. A number of 'knowledge actions' can take place, according to the task or activity for which the knowledge is required such as making the decision or selecting an option. Knowledge actions can be supported by technology, for example, decision support systems and artificial intelligence agents.

4. The knowledge process will be constrained and informed by management factors, for example, terms of reference, policies, resource constraints.

5. Environmental factors, including, economic, legal and political factors will also have a bearing on the knowledge action.

6. The knowledge actions will create 'knowledge outcomes' having the necessary knowledge or the ability to produce the desired result from the knowledge action.

7. The 'knowledge potential', for example, the decision or action that produces the required result from the knowledge action is achieved.

The AR into the components of the KnoVal chain is described in detail in the following section:

\section{Knowledge requirements}

It was first necessary to identify the appropriate knowledge workers and organise a series of 'elicitation workshops' involving the knowledge workers and researchers to identify and specify the necessary components of the model. The elicitation sessions purpose was to establish the knowledge outcomes and knowledge results by questions about the knowledge needed to carry out the knowledge workers' role. Discussion about knowledge assets was facilitated by questions about the knowledge they or their function had, but which it could employ more effectively. The questions about the knowledge requirements involved in their work attempted to understand the relevant knowledge requirements. The knowledge workers were also asked to prioritise their top five knowledge requirements (Wijnhoven, 2001) and each of these were considered further in discussions.

\section{Knowledge assets}

The knowledge workers were then asked by the researchers to identify the knowledge assets (e.g. sources of information, access to expertise, records of past experience being applied). In this part of the session the employees were asked to consider a number of aspects of the organisation. These included organisational resources relating to the purpose, strategy and culture of the organisation contained in formal computer-based IS. Consideration was given to knowledge assets contained in computer-based forms, including reports, personal notes and the minutes of meetings. Discussions also covered personal knowledge that is held by the knowledge workers but which is not currently held in either computer-based or other forms (i.e. tacit/implicit knowledge).

Another action identified by this research was for Britvic to carry out an audit of the knowledge assets that it owns. This primarily consists of explicit information in computer systems and documentary record systems. The managers and knowledge workers were encouraged to review the sources of data and information that were used to carry out their everyday work. The broad categories of information on which knowledge actions are based were computer-based systems and other knowledge assets. In terms of computer-based systems, Britvic had an effective range of IS applications, each supported by an efficient and well-planned IT infrastructure linking all parts of the organisation. Both external and internal information-based knowledge assets were at the firm's disposal. Externally available industry databases provided useful information about market data that were valuable in indicating sales and market trends. Similarly external databases and commercial financial data were identified as useful for highlighting buying patterns. For example, consumer data, indicating buying patterns and trends of the public at large (i.e. consumers) that may affect Britvic's sales and promotions, including the proceedings of relevant conferences, books, independent reports and company presentations.

The current Britvic systems from which the internal knowledge assets could be extracted included databases (corporate and local), 'shared areas' and the company intranet. A number of explicit knowledge assets were identified as existing in Britvic in the form of 'soft' 
information such as sales performance databases and financial systems. Also included in this category were the results of market research surveys and 'attitude studies'. Results from analyses of customer accounts using approaches such as data mining were also available. Details of innovations and 'breakthroughs' were also captured and potentially available as knowledge assets. Longitudinal data in terms of cost/profit by brands and product families were another valuable internal knowledge asset. This phase also identified the existence and importance of product panel diaries and minute of meetings and category strategies and assessment findings.

\section{Knowledge actions}

The elicitation sessions then moved on to identify the knowledge actions. Of interest here were the knowledge outcomes in terms of how they were produced and who was producing them. It was also important to understand what it was that would produce the knowledge outcome or knowledge result. Clearly it was also necessary to explore how the knowledge resource or result was used, by whom and when they would use it. Based on these requirements questions were formulated to be put to the knowledge workers.

As a result of these questions, a number of specific and repeated knowledge actions were identified as existing in the operations of Britvic and were discussed in detail at the workshops. An important knowledge action was the acquisition of new knowledge assets in the form of bought-in or 'threshold' knowledge. This could either be permanently through staff recruitment or temporarily through consultancy services. These knowledge workers often relied upon searches for information by using library or search-engine resources. Existing knowledge bases would be updated through, for example, training or knowledge sharing workshops. Another important knowledge action was the selection of specific existing knowledge assets and the identification of knowledge requirements for use in certain situations such as decision making, resource allocation and investment. The generation of new knowledge assets from existing knowledge bases within the firm for specific or general purposes by combining knowledge from different departments or functions to produce an overall plan or strategy was recognised as a valuable knowledge action. Knowledge workers would internalise, disseminate or share knowledge within Britvic, through spreading expertise from a small number of experts to a larger number of knowledge workers. Work with outside suppliers and customers about operational requirements or marketing activities was recognised as an externalisation or 'dissemination of information' knowledge action.

\section{Management factors}

At this stage in the workshops, it was necessary to identify the common management influences that informed the model of the knowledge actions. The workshops included both managers and knowledge workers, and the researchers again acted as facilitators. To facilitate the process the following common management roles were used to guide the discussions: leadership, co-ordination, control and measurement. In considering the leadership influences effective management of knowledge assets and knowledge manipulation skills (e.g. organising training courses, etc.) and the creation of conditions that are conducive to sharing relevant knowledge in Britvic (e.g. organising workshops and 'networking') were explored. Coordination was explored by including the influences on the scheduling of work that involves and affects knowledge flows and knowledge actions, the alignment of the knowledge activities with the business strategy (i.e. making sure that the knowledge workers have the necessary knowledge that will allow Britvic to compete) and the development of an integrated reward and incentive systems that enable and encourage knowledge dissemination (e.g. suggestion schemes and reward for sharing knowledge in situations that benefit Britvic). Control was considered based on the way in which the management of Britvic manage the provision of knowledge assets including the quantity and quality of the knowledge assets used by Britvic, access and security issues relating to confidential or sensitive information and knowledge assets and constraints (e.g. cost and time) on the acquisition of knowledge assets. Measurement has been cited as one of the most important influences on KM (Wiig, 1993). This research, looked at factors such as assessing and measuring the value of knowledge assets (e.g. cost/benefit analysis of KM tools and IT infrastructure, measuring the use of knowledge manipulation skills and activities (e.g. staff appraisal) and evaluation of the results of knowledge actions (e.g. post-audit and debriefing events).

\section{Environmental factors}

The purpose of this stage in the process of conducting the elicitation workshops was to identify the environmental influences that affected the knowledge actions. These workshops also included managers and knowledge workers, and the researchers again acted as facilitators. The aim of the workshops was to identify and discuss the factors that constrain or enable the knowledge actions. In order to facilitate the process the two common environmental scanning models were used to guide the discussions. The GEPSE model, which has previously been applied in the KM arena (e.g. Joshi, 2001), was used to prompt the examination of a number of factors. Michael Porter's industry competition analysis (or 'five forces') framework (Porter, 1980) was used to examine the 'market forces' to which Britvic will seek to respond, or which it will seek to exploit.

\section{Knowledge outcomes}

The next series of workshops was organised to agree and set 'knowledge outcomes' - the objectives for the 
knowledge actions by which the value of the knowledge outcomes and knowledge results would be judged. At these workshops the knowledge workers and managers were encouraged by the researchers acting as facilitators to identify from their own personal work-related objectives improvements that they would like to see in their use of knowledge. This could include availability of knowledge requirements, access to knowledge assets, knowledge manipulation itself or awareness of knowledge influences, all of which were discussed in the previous workshops.

\section{Knowledge potential}

The next series of workshops in the AR project was organised to agree the actions that would be necessary to help achieve the knowledge targets. These workshops also included a group of knowledge workers from the relevant business areas of Britvic with a representative from the researchers acting as the facilitator. In order to improve knowledge sharing it was decided that a number of actions would be carried out. The Brand Managers, Innovation Team and the Account Managers would be involved in the project and to work together at the appropriate stages of future KM development projects. The Brand Managers and Business Development Controllers agreed to arrange introductory meetings to draw brands, sales and buyers together and to ensure that such meetings are held regularly. It was also agreed that the Business Development Managers would report back and share knowledge on the latest findings with the relevant Brand Teams.

The participants in the workshops were clear that it is people in the form of 'knowledge stakeholders' (i.e. 'knowledge workers' and 'knowledge users') who are the important element in developing and using knowledge assets. It was felt that there is a wealth of tacit and implicit knowledge assets in Britvic (e.g. knowledge and experience of competitors' actions and likely actions). Within the firm there were specific Brand Teams and Departmental teams and specialists in customer and consumer insight and innovation. Generally, it was felt that these groups of people were useful knowledge sources, although it was felt that improvements could be made in the use and dissemination of their knowledge. In addition, there were other information assets that could be 'tapped' in the form of regular customers (with whom the staff of Britvic had good communications) and consumers.

\section{Conclusions}

The ALTAR project into KM leads to the conclusion that the contextual definition of knowledge is an important prerequisite to KM development in a typical organisation. Through the application of the KnoVal in the research it was found that the articulation of knowledge requirements (by different functional groups and individuals) is both desirable and possible in a large-scale KM project. Having identified the knowledge requirements it is important to prioritise them in collaboration with the knowledge workers and managers. It was also found that KM development can contribute towards an organisation's IS development strategy, as the ALTAR project had important implications for IS development in Britvic. The results of the ALTAR workshops included a number of recommendations, including the technical integration of the organisation's separate IS applications and the need to have in place processes to improve the extent to which the analytical capabilities of employees (i.e. 'knowledge workers') can be identified and known by managers and directors. Recommendations for improved training in the use of the IS applications and knowledge resources for new and existing staff and to improve the induction programme for new employees to provide a better introduction to the roles of current staff and to provide better knowledge of the organisation's knowledge resources (i.e. 'meta-knowledge') were also made as a result of the ALTAR project.

The research has important implications for the commercial partner, Britvic and for similar organisations that are seeking to initiate and promulgate KM projects. For example, KnoVal assisted the organisation in focussing on essential aspects of KM and the joint definition of knowledge proved useful at the different organisational levels. Knowledge workers and managers found the organisational learning that accrued at the strategic level particularly useful. They appreciated the structure, management and collaborative approach of the ALTAR project (Shah et al., 2007). The research led thinking was useful in helping them to understand the importance of knowledge, what knowledge assets they had and the principles that needed to be embodied in their systems in order for that knowledge to be harnessed. At the operational level, the knowledge workers found the approach to be useful for re-orienteering their thinking and understanding better how to access the knowledge of others and to share their own knowledge with them. The outcomes of the research also had valuable implications for the academic partners in the research project. There was experience in the conduct of an AR/KM project facilitating academic research, organisational change and learning, which provided useful content for teaching and learning, the development of learning materials and research outputs.

\section{Acknowledgements}

The authors would like to thank Britvic Soft Drinks Ltd for permission to publish this research. We are grateful to Rob Pritchard, Head of IT Planning \& Governance, for his vision and inspiration for the ongoing strategic partnership. We would like to thank Dr. Sharon Cox (Birmingham City University) whose work with Britvic was important in establishing the early links. We would particularly like to acknowledge the contribution of the late Alan Forrester, Head of Business Solutions in the IT department at Britvic - it was his vision, inspiration and support that made the University-Industry collaboration, underpinning this work, 
possible. We would also like to thank Chris Haskins for his contribution to this research. We would also like to thank all of the other people at Britvic and the two Universities who

\section{About the Authors}

Trevor Wood-Harper is Professor of Information Systems at Manchester Business School. Professor Wood-Harper's research area is in Information Systems with a focus on multiple perspective systems thinking. He has authored, co-authored or co-edited 21 books and proceedings. He has published over 230 research articles on a wide range of topics. Trevor Wood-Harper in on the editorial boards of the European Journal of Information Systems and Information Systems Journal. These two publications are the leading non-US world-class journals. Wood-Harper has held visiting chairs at the University of Oslo, Copenhagen Business School, Georgia State University, University of South Australia, and currently, at the Australian National University, University Technology Malaysia and Napier University.

Hanifa Shah is Professor of Information Systems and Head of the Informatics and Knowledge Management Group at Staffordshire University. Professor Shah has over 25 years of experience as an IS/IT researcher and also practitioner. She is a Fellow of the British Computer Society. Professor Shah has led both U.K. Research Council (EPSRC) funded and industrially funded research projects. Her research has resulted in publications in helped to make this collaboration a success. These include managers, knowledge workers and researchers and students (especially Amanda, Judith, Nicola, Peter and Sarah). international journals such as Communications of the ACM, European Journal of Infomation Systems and Information Technology \& People. She has research interests in a number of areas including the development of IS/IT systems, enterprise architecture, knowledge management, learning through action research and the professional development of IS/IT Employees in industry. She has recently been awarded a Royal Academy of Engineering funded Secondment into Industry.

Alan Eardley is currently Associate Head of Postgraduate Research Studies in the Faculty of Computing, Engineering and Technology at Staffordshire University, where he teaches Knowledge Management and Research Methods to postgraduate students and supervises research students in the above areas. He has co-authored five texts on Information Management, some of which were adopted as texts by professional bodies, and has contributed chapters to a number of recent books on Knowledge Management. He has also co-authored a number of research articles, some in leading international journals, in Information Systems Management and Knowledge Management, with a particular interest in the application of Knowledge Management in an organisational context.

\section{References}

ABELL A and OXBROW N (2001) Competing with Knowledge: The Information Professional in the Knowledge Management Age. TFPL Library Association Publishing, London.

ALAVI M and LEIDNER DE (2001) Review: knowledge management and knowledge management practices: conceptual foundations and research issues. MIS Quarterly 25(1), 107-136.

ARGYRIS C (1999) On Organizational Learning, 2nd edn. Blackwell, Oxford.

BASILI VR and ROMBACH HD (1991) Support for comprehensive reuse. Software Engineering Journal 6(5), 303-316.

BASKERVILLE R and WOOD-HARPER AT (1998) Diversity in information systems action research methods. European Journal of Information Systems 7(2), 90-107.

BECKMAN TJ (1999) The current state of knowledge management. In Knowledge Management Handbook (LIEBOWITZ J, Ed), CRC Press, Florida.

Bolsot MH (1998) Knowledge Assets: Securing Competitive Advantage in the Knowledge Economy. Oxford University Press, Oxford.

BUCKLER B (1998) Practical steps towards a learning organisation: applying academic knowledge to improvement \& innovation in business process. The Learning Organisation 5(1), 15-23.

CARNEIRO A (2000) How does knowledge management influence innovation and competitiveness? Journal of Knowledge Management 4(2), 87-98.

Erat P, Desouza KC, SChäfer-Jugel A and KurzaWa M (2006) Businesscustomer communities and knowledge sharing: exploratory study and critical issues. European Journal of Information Systems 15(5), 522-524.

GRANT RM (1996) Prospering in dynamically-competitive environments: organizational capability as knowledge integration. Organization Science 7(4), 375-387.

HILDRETH P and KIMBLE C (2002) The duality of knowledge. Information Research 8(1), Paper No. 142. (Available at http://InformationR.net/ir/ 8-1/paper142.html,Accessed 30 March 2007).

HOLSAPPLE CW and JOSHI KD (2001) Knowledge management: a three fold framework. The Information Society 18(1), 47-64.

HowARD-GrenVILLE JA and CARLILE PR (2006) The incompatibility of knowledge regimes: consequences for the material world for cross domain work. European Journal of Information Systems 15(5), 443-485.

JENNEX M (Ed) (2005) Case Studies in Knowledge Management. Idea Group Publishing, Hershey, PA.

JOSHI KD (2001) A framework to study knowledge management behaviors during decision making. Proceedings of the 34th International Conference on Systems Sciences (SPRAGUE RH, Ed), IEEE Computer Society, Washington, DC.

KELLEHER D and LEVENE S (2001) Knowledge Management - A Guide to Good Practice. British Standards Institution, London.

LIEBESKIND JP (1996) Knowledge, strategy, and the theory of the firm. Strategic Management Journal 17(Special Issue), 93-108.

MARLER K (1999) Rapid emerging knowledge deployment. Crosstalk: The Journal of Defence Software Engineering 12(11), 14-16.

MAY D and TAYLOR P (2003) Knowledge management with patterns: developing techniques to improve the process of converting information into knowledge. Communications of the ACM 46(7), 94-99.

NEWMAN BD and CONRAD KW (2000) A framework for characterizing knowledge management methods, practices, and technologies. In PAKM 2000, Third International Conference on Practical Aspects of Knowledge Management, Proceedings of the Third International Conference (REIMER U, Ed) Basel, Switzerland, October 30-31 CEURWS.org, CEUR workshop Proceedings, Vol. 34, pp 16.1-16.11. 
NONAKA I and KONNO N (1998) The concept of 'Ba': building a foundation for knowledge creation. California Management Review 40(3), 40-54.

O'Dell C and Grayson CJ (1998) If Only We Knew What We Know: The Transfer of Internal Knowledge and Best Practice. The Free Press, New York.

ORLIKOWSKI WJ (2006) Material knowing: the scaffolding of human knowledgeability. European Journal of Information Systems 15(5), 460-466.

POLANYI M (1967) The Tacit Dimension. Anchor Books, New York.

PORTER MJ (1980) Competitive Strategy. Free Press, New York.

PRUSAK L (2001) Where did knowledge management come from? IBM Systems Journal 40(4), 1002-1007.

SHAH HU, EARDLEY WA and WOOD-HARPER AT (2007) ALTAR: Achieving Learning Through Action Research. European Journal of Information Systems 16, 6.

SHARKIE R (2003) Knowledge creation and its place in the development of sustainable competitive advantage. Journal of Knowledge Management 7(1), 20-31.

SHARP PJ (2004) MaKE - a knowledge management method. PhD Thesis, Staffordshire University, UK.

SHARP PJ, EARDLEY WA and SHAH HU (2002) Evaluating knowledge in organisations holistically as part of an information systems development strategy. Proceedings of the Third International Symposium on Communication Systems, Networks and Digital Signal Processing 15-17 July, pp. 193-196.

SHARP PJ, EARDLEY WA and SHAH H (2003) Visual tools within MakE - a knowledge management method. Electronic Journal of Knowledge Management 1(2), 177-186.

ShaRP PJ, SimM M, EARDLEY WA and SHAH H (2005) MaKE First Steps - a Practical Approach to Collaboratively Defining Knowledge in Organisations. In Proceedings of the Second International Conference on Intellectual Capital, Knowledge Management and Organisational Learning, American University in Dubai, UAE, 2005, pp 439-459.
SPEIGLER I (2000) Knowledge management: a new idea or a recycled concept? Communications of the Association of Information Systems 3(4), 14

SPENDER J-C (1996) Organizational knowledge, learning and memory: three concepts in search of a theory'. Journal of Organizational Change Management No. 9, 63-78.

SUSARLA A, LIU D and WHINSTON AB (2003) Peer-to-peer enterprise knowledge management. In Handbook on Knowledge Management 2: Knowledge Directions (HolSAPPLE CW, Ed), pp 129-139, Springer-Verlag, New York.

SVEIBY KE (1997) The New Organizational Wealth: Managing \& Measuring Knowledge-Based Assets. Berrett-Koehler Publishing, San Francisco.

SWAN J (2006) Commentary on Wanda Orlikowski's, 'material knowing: the scaffold of human knowledgeability'. European Journal of Information Systems 15(5), 467-469.

TEECE DJ (1998) Research directions for knowledge management. In California Management Review: Special Issue on Knowledge and the Firm 40(3), 289-292.

TOPI H, LUCAS W and BABAIAN T (2006) Using informal notes for sharing corporate technology know-how. European Journal of Information Systems 15(5), 486-499.

WIIG KM (1993) Knowledge Management Foundations. Schema Press, Texas.

WIIG KM (1997) Knowledge management: where did it come from and where will it go? Expert Systems with Applications 13(1), 1-14.

WIJNHOVEN F (2001) A framework for stakeholder-based knowledge valuation in organizations. In Knowledge Management and Business Model Innovation (YocesH M, Ed), pp 298-315, Idea Group Publishing, Harrisburg (PA).

YU JE (2004) Reconsidering participatory action research for organizational transformation and social change. Journal of Organisational Transformation and Social Change 1(2), 111-141. 